Journal of Research in Science Teaching, 1986, 23, 727-737

\title{
COGNITIVE RESTRUCTURING AS AN EARLY STAGE IN PROBLEM SOLVING
}

\author{
GEORGE M. BODNER and THERESA L. B. McMILLEN \\ Department of Chemistry, Purdue University, West Lafayette, Indiana 47907
}

\begin{abstract}
This article examines the hypothesis that them are preliminary stages in problem solving which most chemists neglect when trying to teach their students how to solve problems in introductory chemistry courses. It is during these early stages that relevant information is disembedded from the question and the problem is restructured. Unless students can successfully complete these cognitive restructuring stages, they cannot proceed on to the more analytic stages in problem solving that have received more attention from chemists.

Preliminary evidence for this hypothesis consists of linear correlations between student ability to handle disembedding and cognitive restructuring tasks in the spatial domain and their ability to solve chemistry problems.
\end{abstract}

\section{Introduction}

Only a fraction of the students who take chemistry at either the high school or college level are volunteers; the vast majority were drafted. They are there because someone told them that a high school chemistry course will help prepare them for college, or because a college-level course is a requirement for their major.

Students are required to take chemistry for many reasons. Some people argue that students need to be introduced to the language chemists use to describe the world we live in because it is a language used by so many other disciplines. Others believe that students need to be exposed to the characteristic analytic thought processes chemists use to interpret the results of experiments run on the macroscopic scale in terms of the structure of a sub-microscopic world they can never see. We believe there is a third reason, chemistry courses are ideal places to help students learn how to solve problems.

To some, problem solving in chemistry involves learning how to do gram-gram calculations or titration problems. To us, it is much more. It includes a ,variety of tasks ranging from predicting the products of the reaction between strontium and water to deciding that polonium crystallizes in a simple cubic unit cell on the basis of measurements of the density of the metal and the distance between adjacent planes of atoms in the crystal.

\section{Differentiating between Problems and Exercises}


Hayes' (1980) operational definition of a problem provides a basis for distinguishing between two closely related concepts: problems and exercises.

Whenever there is a gap between where you are now and where you want to be, and you don't know how to find a way to cross that gap, you have a problem.

According to this definition, if you know what to do when you read a question, it's an exercise, not a problem. Status as a problem is not an innate characteristic of a question; it is a subtle interaction between the question and the individual trying to answer the question.

The following question, which was used in a study of problem solving at Purdue University (Greenbowe, 1983), would be a problem for most chemistry students, but not necessarily for most chemists.

A 2.395 $\mathrm{g}$ sample of an unknown chloride with the formula $\mathrm{MCl}_{3}$ is dissolved in water and treated with excess silver nitrate solution. The mass of the $\mathrm{AgCl}$ precipitate formed is $5.168 \mathrm{~g}$. What is the atomic weight of the unknown metal'? (Boikess \& Edelson, 1978)

Many chemists, particularly those who teach general chemistry regularly, know how to attack this question as soon as they understand it. They have worked so many stoichiometry questions that they realize, almost as soon as they read the question, that knowing the weight of $\mathrm{MCl}_{3}$ present initially is worthless unless one also knows the number of moles of $\mathrm{MCl}_{3}$. They therefore automatically turn to the other number, the known weight of $\mathrm{AgCl}$, calculate the weight of a mole of this compound by referring to a table of atomic weights, and convert grams of $\mathrm{AgCl}$ into moles of $\mathrm{AgCl}$.

$$
5.168 \mathrm{~g} \mathrm{AgCl} \times \frac{1 \mathrm{~mol} \mathrm{AgCl}}{143.32 \mathrm{~g} \mathrm{AgCl}}=3.606 \times 10^{-2} \mathrm{~mol} \mathrm{AgCl}
$$

They then recognize the 3:1 relationship between moles of $\mathrm{AgCl}$ and moles of $\mathrm{MCl}$, either from reading the question or by writing a chemical equation, and calculate the number of moles of $\mathrm{MCl}_{3}$ present initially.

$$
3.606 \times 10^{-2} \mathrm{~mol} \mathrm{AgCl} \times \frac{1 \mathrm{~mol} \mathrm{MCl}_{3}}{3}=1.202 \times 10^{-2} \mathrm{~mol} \mathrm{MCl}_{3}
$$

They then divide the number of grams of $\mathrm{MCl}_{3}$ in the sample by the number of moles to get the molecular weight of the compound

$$
\frac{2.395 \mathrm{~g} \mathrm{MCl}_{3-}}{1.202 \times 10^{-2} \mathrm{~mol}}=199.3 \mathrm{~g} / \mathrm{mol}
$$


and subtract the weight of the three chlorine atoms $(35.453 \mathrm{~g} / \mathrm{mol})$ from the molecular weight to get the atomic weight of the metal $(92.9 \mathrm{~g} / \mathrm{mol})$. Although the question did not ask for this information, any reputable chemist would then compare this answer with the data in the Periodic table to see whether there is in fact a metal with this atomic weight.

We might be able to turn this question into a problem for virtually everyone, however, by pulling out some of the hints that tell us how to tackle the question.

A $2.395 \mathrm{~g}$ sample of an unknown chloride is dissolved in water and treated with an excess of a common reagent that precipitates the $\mathrm{Cl}$ - ion. The mass of the precipitate formed is $5.168 \mathrm{~g}$. What is the atomic weight of the unknown metal?

\section{Differentiating between Algorithms and Heuristics}

At least part of the trouble students have with problem solving in introductory chemistry courses might be attributed to the fact that chemists have historically tried to teach their students how to solve problems by doing nothing more than working examples. In recent years, however, chemists have begun to realize the importance of general strategies or heuristics in problem solving, and they have become particularly enthralled with the "road map" approach to stoichiometry calculations. This technique recommends doing gramgram calculations, for example, by constructing a map of the steps that have to be taken to get from grams of one reactant (or product) to grams of another.

$$
\text { grams of reactant } \rightarrow \text { moles of reactant } \rightarrow \text { moles of product } \rightarrow \text { grams of product }
$$

The popularity of this technique among chemists is not surprising when you consider that this is exactly the sequence of steps we suggested that chemists would use to answer the question in the previous section.

There is abundant evidence that some students never learn how to use road maps successfully. Why not? Perhaps because there are stages in problem solving that students must successfully complete before they can get to the analytic stage where the logical sequence of steps that characterize the road map approach can be useful.

There is also abundant evidence that students who can successfully use the road map approach to gram-gram calculations often cannot answer limiting reagent questions such as, "How many grams of $\mathrm{CO}_{2}$ are produced when 10.0 grams of glucose react with 10.0 grams of oxygen?" Why not? Perhaps because the road map approach is not an example of a general strategy or heuristic for solving stoichiometry problems. It's an example of an algorithm that is useful for solving exercises, but not sufficient for solving problems.

Algorithms are useful for teaching students how to work sets of familiar exercises. But it is unrealistic to expect students to use any but the simplest algorithms when faced with a question that satisfies Hayes' definition of a problem. The difference between using algorithms to solve exercises and general strategies or heuristics to solve problems might 
best be illustrated by Wheatley's (1984) definition of problem solving as "what you do when you don't know what to do."

\section{Stages in Problem Solving}

Forty years ago, Polya (1945) suggested that there are four stages in solving a problem.

(1) Understanding the problem.

(2) Devising a plan.

(3) Carrying out the plan.

(4) Looking back.

More recently, Hayes (1980) expanded this list to include six steps.

(1) Finding the problem. (Recognizing that a problem exists.)

(2) Representing the problem. (Understanding the gap to be crossed.)

(3) Planning the solution. (Choosing a method for crossing the gap.)

(4) Carrying out the plan.

(5) Evaluating the solution. (How good is the result'?)

(6) Consolidating gains. (Learning from the experience of solving the problem.)

No matter whose model of problem solving we use, there is invariably an early stage whose goal is understanding the problem, or finding the problem. We would like to suggest that this is a holistic or gestalt stage where relevant information is "disembedded" from the problem, and the elements of the problem are juggled more or less simultaneously until the problem is "restructured" or transformed into a problem that the student understands (i.e., a problem for which the student recognizes the initial and goal states). Unless students can get through this stage successfully, they can't solve the problem regardless of how well they understand the analytic processes involved in answering similar questions.

We use the term restructuring in the sense of cognitive restructuring, one of the concepts isolated from studies of field dependence-independence (Linn \& Kyllonen, 1981). An appropriate mental image of the task involved in disembedding might be conjured up by noting that "embedded" is defined as being firmly fixed in a surrounding mass.

Chemists are so familiar with typical chemistry problems that they often forget what a challenge it is for beginning students to successfully disembed relevant information and restructure a problem. Perhaps the best way of demonstrating that even proficient chemistry problem solvers go through a stage in which disembedding and restructuring occurs is to ask the reader to envision answering the following question from a recent college text (Bailar, 1984).

A particular electrochemical cell consists of one half-cell in which a silver wire coated with $\mathrm{AgCl}(\mathrm{s})$ dips into a I $\mathrm{M} \mathrm{KCl}$ solution and another haft-cell in which a piece of platinum dips into a solution that is 0 . I M in $\mathrm{CrCl}_{3}, 0.001 \mathrm{M}$ in $\mathrm{K}_{2} \mathrm{Cr}_{2} \mathrm{O}_{7}$, and 
$1 \mathrm{M}$ in $\mathrm{HCl}$. In the cell described, the following reaction takes place:

$\mathrm{Ag}(\mathrm{s})+\mathrm{Cr}_{2} \mathrm{O}_{7}^{2-}+\mathrm{Cl}^{-}+\mathrm{H}^{+} \rightarrow \mathrm{AgCl}(\mathrm{s})+\mathrm{Cr}^{3+}+\mathrm{H}_{2} \mathrm{O}(\mathrm{l})$

The standard reduction potentials are $1.33 \mathrm{~V}$ and $0.22 \mathrm{~V}$ for the $\mathrm{Cr}_{2} \mathrm{O}_{7} / \mathrm{Cr}^{3+}$ and $\mathrm{AgCl}(\mathrm{s}) / \mathrm{Ag}, \mathrm{Cl}^{-}$couples, respectively. Write (a) the ion-electron equations for the half-reactions in this cell and the overall cell equation. Determine (b) the standard state potential and (c) the potential of the cell under the above nonstandard conditions. (d) Calculate the equilibrium constant for the reaction.

The reader's ability to solve this problem (or lack thereof) is not as important as the activities he or she goes through while trying to set up the problem. We believe that the same disembedding and restructuring skills "experts" use to turn this question into a problem they can solve must be used by students when they tackle much simpler questions such as predicting how much $\mathrm{CO}_{2}$ is given off when 10.0 grams of glucose react with 10.0 grams of $\mathrm{O}_{2}$, or even how much $\mathrm{CO}_{2}$ is produced when 10.0 grams of glucose react with excess $\mathrm{O}_{2}$.

\section{Experimental Evidence}

Our attention was focused on the importance of early stages in problem solving by the results of studies of the correlation between student performance on spatial tasks and their performance in general or organic chemistry. Our original goal was to look at differences between the performance of "high" and "low" spatial ability students on highly spatial concepts in chemistry. The preliminary experiments described in this article led us to examine the relationship between scores on spatial ability tests and problem solving performance as well.

\section{Method}

\section{Sample}

The subjects of this study were enrolled in the first half (CHM 115) of a two-semester general chemistry sequence for students majoring in science, engineering, pharmacy, veterinary medicine and related areas at Purdue University. Between 35 and 40 percent of the 4500 to 5000 general chemistry students at Purdue each fall are enrolled in one of the two sections of CHM 115. In the fall of 1982, when this study was done, the total enrollment in both sections of CHM 115 was 1839 students. The average SAT math and verbal scores for this population were 576 and 486, respectively (Greenbowe, 1983).

Because different exams were used in the two sections, this study was restricted to the larger section which had an initial population of slightly more than 1100 students. The sample was then further restricted to the 587 students for whom a complete set of chemistry performance, spatial ability, and SAT math and verbal scores were available (McMillen, 1983). 


\section{Tests}

A battery of four tests was used to measure spatial ability. The ROT test is a 20 -item version of the Purdue Visualization of Rotations Test (Guay \& McDaniel, 1978) which has been characterized as a measure of spatial visualization (Bodner, Carter, \& Guay, in press), and therefore a measure of cognitive restructuring in the spatial domain (Ekstrom, French, \& Harman, 1976). Guay, McDaniel, \& Angelo (1978) found the ROT test to be one of the measures of spatial ability which is least likely to be confounded by analytical processing. A time limit of 10 minutes was used in this study to further restrict analytical processing. The directions for this exam tell the student to:

(1) study how the object in the top line of the question is rotated, (2) picture in your mind what the object shown in the middle line of the question looks like when rotated in exactly the same manner, and (3) select from among the five drawings $(A, B, C, D$, or $E)$ given in the bottom line of the question the one that looks like the object rotated in the correct position.

Item 7 from the ROT test is shown in Figure 1. Students were given one point for each of the 20 items they answered correctly (McMillen, 1983; $\mathrm{M}=13.84, \mathrm{~N}=1273, S D=3.84$, $\left.K R_{20}=0.80\right)$.

The Find-A-Shape-Puzzle (FASP) is an adaptation of Gottschaldt's Figures test which measures disembedding in the spatial domain (Linn, Pulos, \& Gans, 1981; Linn \& Kyllonen, 1981). This test consists of four pages, one of which is shown in Figure 2. Each page contains a simple figure and five complex figures in which the simple figure is embedded. The subjects were given 60 seconds per page to find and shade in the simple figure in each of the five complex figures, and given one point for each of the $20 \mathrm{complex}$ figures in which the simple figure was correctly located (Carter, 1984; $M=12.71, N=1652$, $S D=5.58$, Cronbach's alpha $=0.90)$.

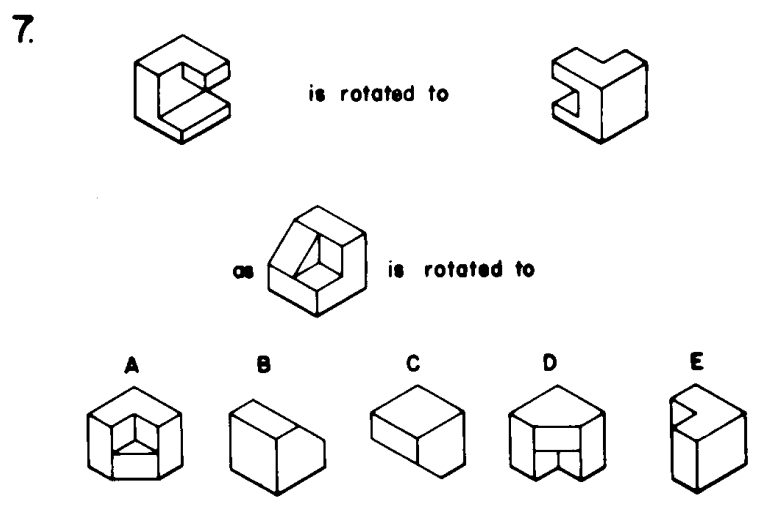

Fig. 1. One question from a 20-item test of cognitive restructuring in the spatial domain known as the Purdue Visualization of Rotation test. Copyright, Purdue Research Foundation. 


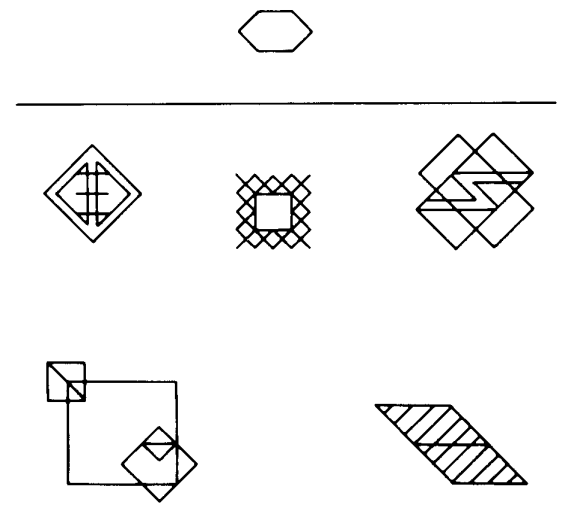

Figure 2. One page of a four-page, 20-item test of disembedding in the spatial domain known as the Find-A-Shape-Puzzle

EMBF $(M=21.9, N=587)$ and SUCF $(M=23.0, N=587)$ are 25 -item subscores of a 50 item film test (McDaniel, 1974; KR20 EMBF $=0.74$, SUCF $=0.75$, total $=0.84$ ). EMBF is an embedded figures test in which subjects are shown a simple figure for three seconds. The screen then goes blank for one second, an array of four designs is presented for one second, and the subjects are asked to indicate which of the designs contains the original figure. SUCF is a successive figures test in which the subjects are shown three or four lines, one at a time, and then asked which of four designs represents the pattern formed by these lines when viewed simultaneously.

Four subscores were used to measure chemistry performance. Subscore I included nine multiple-choice questions on stoichiometry from the first hour exam. Subscore 2 contained nine multiple-choice questions on the structures of metallic and ionic solids from the third exam. Subscore 3 was a free-response crystal structure quiz given during the laboratory which asked students to build a model of the unit cell of a crystal they had not seen previously, and then determine the formula of the compound, the coordination numbers of the atoms in the crystal, and at least one interatomic distance in the crystal. Subscore 4 was a 40 -item, multiple-choice comprehensive final exam. Examples of questions from subscores 1 and 2 , and a complete listing of the questions in one of the six versions of the crystal quiz are given in Table $\mathrm{I}$.

\section{Statistical Procedure}

The SPSS programs operating on the Purdue University Computer Center system were used to calculate Pearson product-moment coefficients for the correlations between spatial scores and performance on the chemistry subscores. Scores on each of the spatial tests correlated with performance on the other three spatial tests at a significance level of $p<$ 0.001 or better. Scores on each of the spatial tests also correlated with performance on all four chemistry subscores at a significance level of $p<0.005$ or better. A total spatial score was therefore calculated for each student by summing the T-scores on EMBF, SUCF, ROT 
and FASP.

Results

As expected, there is a statistically significant correlation between the students' performance on the spatial tests in this study and their performance on highly spatial concepts in chemistry such as the structures of metallic and ionic solids as shown by the Pearson product-moment coefficients for subscores 2 and 3 given in Table II.

TABLE II

Correlations between Total Spatial Score and Chemistry Subscores

\section{Sub-score}

1. Multiple-choice questions on stoichiometry

$r=.29^{*}$

from the first hour exam

2. Multiple-choice questions on crystal

$r=.32^{*}$ structure from the third hour exam.

3. Free-response quiz on crystal structures $\quad r=.35^{*}$

4. Comprehensive first-semester final exam $r=.30^{*}$

${ }^{*} p<0.0001$

What was less expected is the finding that the correlations between the total spatial score and the students' performance on multiple-choice stoichiometry questions (sub-score 1) or the comprehensive final exam (subscore 4) were comparable, within experimental error, to the correlations between the total spatial score and the highly spatial crystal structure questions. 


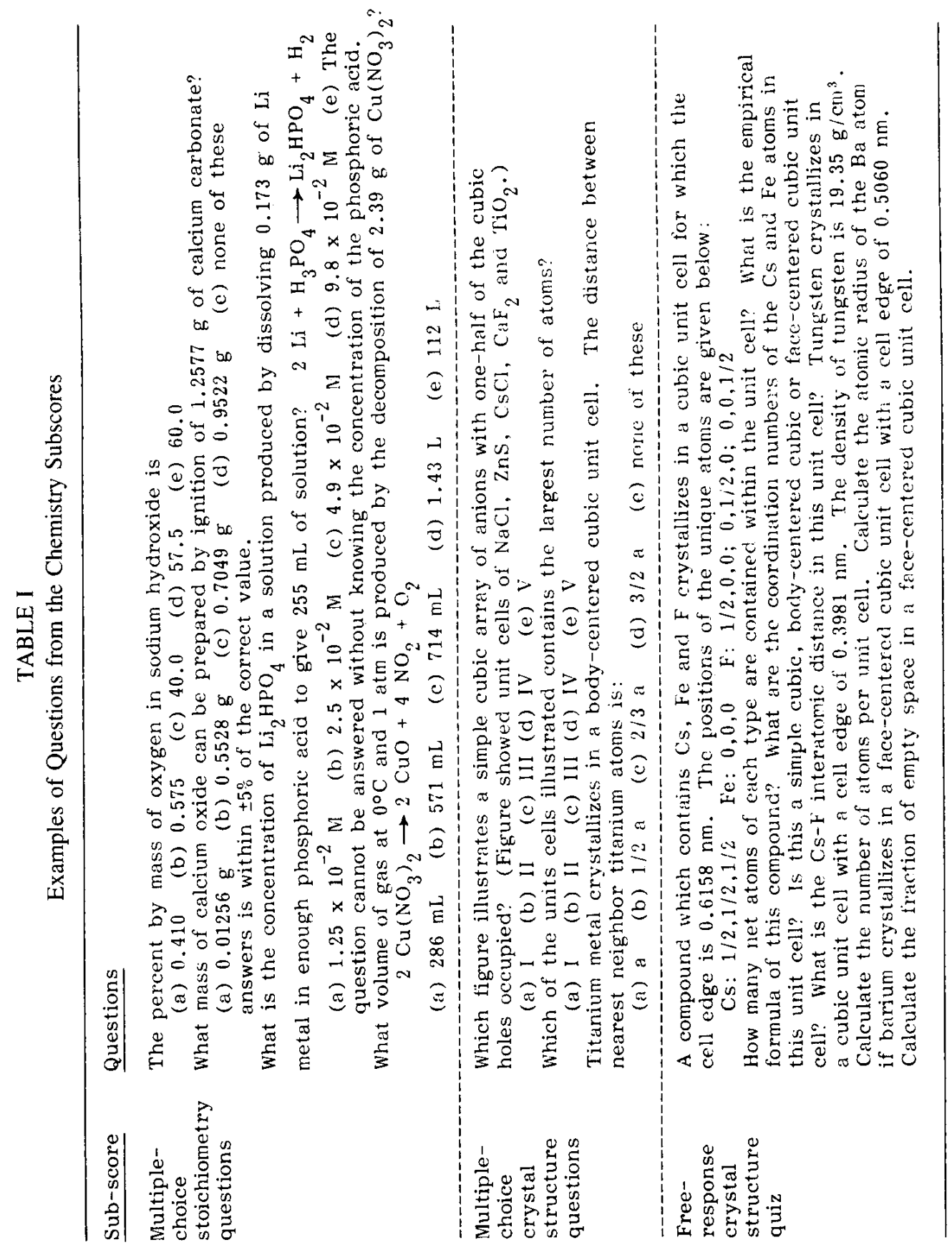




\section{Discussion}

Although they are far from conclusive, these results are consistent with the hypothesis that there exists an early holistic or gestalt stage in problem solving in which students must disembed relevant information from a question and restructure the problem.

In retrospect, it is not surprising that the correlations for highly spatial questions (subscores 2 and 3 ) are not significantly larger than for questions that on the surface bear no apparent relation to spatial ability (subscores 1 and 4), because the questions in subscores 2 and 3 ask students to do far more than simply rotate two-dimensional models of threedimensional figures or disembed information from a complex spatial figure. After the student has completed these tasks, he or she must use the results of this analysis to solve a problem. Thus, it can be argued that these questions test problem solving ability in much the same way as the questions in subscores I and 4.

\section{Implications of this Model of Problem Solving}

It is possible that much of what we now do to teach problem solving in chemistry is misdirected because it reflects what experts do when they work an exercise instead of what they do when they work a true problem, and neglects the early steps in problem solving which set the stage for the analytic thought processes that eventually lead to an answer.

It is also possible that chemists can improve their students' problem solving ability by telling their students what they do when they solve a real problem, not just another familiar exercise. It is likely that when chemists solve real problems, they go through a sequence of steps in which they first read the question, write down what they hope is the key information, reread the question, draw a picture to help represent the question, read the question once more, and then try something. Then they try something else. Then they try to see how far they've gotten towards an answer. By gradually exploring the problem, they eventually get an answer, at which point they might construct an algorithm for solving similar questions in the future.

If this sequence of steps comes close to describing what chemists do when they solve a problem, it should be kept in mind when we work with students. It should remind us to help students learn how to get to the point where they can use the analytic processes that lead to an answer.

\section{Acknowledgment}

We would like to acknowledge the assistance of Tom Greenbowe and Ernest McDaniel in both the collection and initial analysis of the data in this study, and the invaluable contributions of John Staver and two anonymous reviewers to the revision of this manuscript. 


\section{References}

Bailar, J. C., Jr., Moeller, T., Kleinberg, J., Guss, C. O., Castellion, M. E., \& Metz, C. (1984). Chemistry, second edition. New York: Academic.

Boikess, R. S., \& Edelson, E. (1978). Chemical principles. New York: Harper and Row.

Bodner, G. M., Carter, C. S., \& Guay, R. (in press). The Purdue visualization of rotations test, Journal of Research in Science Teaching.

Carter, C. S. (1984). A study of the relationships between spatial ability, sex, and success in general chemistry. Unpublished master's thesis, Purdue University, West Lafayette, IN.

Ekstrom, R. B., French, J. W., \& Harman, H. H. (1976). Manual for kit of factor referenced cognitive tests. Educational Testing Service, Princeton, NJ.

Greenbowe, T. J. (1983). An investigation of variables involved in chemistry problem solving. Unpublished doctoral dissertation, Purdue University, West Lafayette, IN.

Guay, R., McDaniel, E., \& Angelo, S. (1978). Analytic factor confounding spatial ability measurement. Paper presented at the meeting of the American Psychological Association, Toronto, Ontario, Canada.

Guay, R. B. \& McDaniel, E. (1978). Correlates of performance on spatial aptitude tests. Final Report for the U.S. Army Research Institute.

Hayes, J. R. (1981). The complete problem solver. Philadelphia: The Franklin Institute Press.

Linn, M. C. \& Kyllonen, P. (1981). The field dependence-independence construct: Some, one, or none. Journal of Educational Psychology, 73, 261-273.

Linn, M. C., Pulos, S., \& Gans, A. (1981). Correlates of formal reasoning: content and problem effects. Journal of Research in Science Teaching, 18, 435-47.

McDaniel, E. D. (1974). Development of a group test for assessing perceptual abilities. Perceptual and Motor Skills, 39, 669-670.

McMillen, T. L. B. (1983). A study of the relationship between spatial ability, ,field dependence-independence, and achievement in chemistry. Unpublished master's thesis, Purdue University, West Lafayette, IN.

Polya, G. (1945). How to solve it: A new aspect of mathematical method. Princeton, $\mathrm{N} \mathrm{J}$ : Princeton University Press.

Wheatley, G. H. (1984). Problem solving in school mathematics. MEPS Technical Report 84.01, School Mathematics and Science Center, Purdue University, West Lafayette, IN. 